\title{
ANÁlISE TÉCNICA DE SISTEMAS DE TORREFAÇÃO PARA APROVEITAMENTO DA BIOMASSA NA GERAÇÃO DE ENERGIA
}

\author{
J.A.M. CARNEIRO Jr ${ }^{1}$, E.A. TORRES ${ }^{1}$ e C.T. ALVES ${ }^{1}$ \\ ${ }^{1}$ Universidade Federal da Bahia, Escola Politécnica, Programa de Engenharia Industrial - Laboratório \\ de Energia e Gás \\ E-mail para contato: jamcarneiro@yahoo.com.br
}

\begin{abstract}
RESUMO - Neste estudo foi observado que os desafios técnicos no desenvolvimento da tecnologia de torrefação passam pelo manuseio do gás de processo contaminado, o aumento de escala do processo, previsibilidade e consistência da qualidade do produto, densificação da biomassa torrefeita, o uso da integração energética e a flexibilidade na utilização de diferentes matérias-primas no processo. Dessa forma, objetiva-se comparar as diversas tecnologias utilizadas em bancada, estendendo a análise para diferentes experiências industriais, trazendo aspectos das tecnologias do sistema reacional, balanço de massa e balanço energético do processo de torrefação. Assim, para o aproveitamento da energia térmica do processo de secagem e torrefação pode-se, a princípio, ser implementado as seguintes melhorias: recirculação de gases de combustão para aquecimento do processo, a recirculação de "torgas" e recirculação do vapor de processo.
\end{abstract}

\section{INTRODUÇÃO}

A independência e autossuficiência no setor de energia é um indicador do desenvolvimento socioeconômico de qualquer país. Por isso, nos últimos anos as pesquisas e prospecções tecnológicas têm-se voltado ao uso de fontes de energia não convencionais. A utilização da biomassa de forma regulada e eficiente tem sido bastante impulsionada por ser um recurso renovável e de grande abundância no Brasil. A vantagem única sobre as demais fontes de energia limpa é que a biomassa pode ser utilizada para gerar calor e energia de acordo com a exigência industrial ou doméstica, de forma fácil e prática, sendo assim um pilar de grande importância no fornecimento de energia com vistas no presente e no futuro (Basu et al., 2014).

As propriedades inerentes da biomassa crua, como por exemplo, o alto teor de umidade, baixa densidade energética, degradação biológica e alteração de propriedades físico-químicas durante o armazenamento e dificuldade de moagem, limitam sua ampla utilização na indústria. Para superar estas limitações, a torrefação tem sido proposta como um processo de tratamento térmico da biomassa (Arias et al., 2008). Assim, pode-se considerar que a torrefação objetiva eliminar o oxigênio sob a forma de gases de baixo valor calórico, por exemplo, $\mathrm{CO}_{2}$, água e alguns ácidos orgânicos, por exposição da biomassa a temperaturas de $200-300^{\circ} \mathrm{C}$ (Pimchuai et al., 2010; Medic et al., 2012).

Como vantagens técnicas do processo de torrefação da biomassa, por exemplo, podemos 
observar na Tabela 1 algumas características e especificações desejáveis para combustíveis sólidos, comparando informações do carvão mineral e de combustíveis renováveis obtidos a partir da biomassa.

Tabela 1 - Características físico-químicas de diferentes combustíveis sólidos.

\begin{tabular}{|l|c|c|c|c|c|}
\hline & Madeira & $\begin{array}{c}\text { Pellets de } \\
\text { Madeira }\end{array}$ & $\begin{array}{c}\text { Pellets de } \\
\text { Torrefação }\end{array}$ & $\begin{array}{c}\text { Carvão } \\
\text { Vegetal }\end{array}$ & $\begin{array}{c}\text { Carvão } \\
\text { Mineral }\end{array}$ \\
\hline Teor de Umidade (\%peso) & $30-45$ & $7-10$ & $1-5$ & $1-5$ & $10-15$ \\
\hline $\begin{array}{l}\text { Poder Calorifico Inferior } \\
\text { (MJ/kg) }\end{array}$ & $9-12$ & $15-18$ & $20-24$ & $30-32$ & $23-28$ \\
\hline Volateis (\%biom seca) & $70-75$ & $70-75$ & $55-65$ & $10-12$ & $15-30$ \\
\hline Carbono Fixo (\%biom seca) & $20-25$ & $20-25$ & $28-35$ & $85-87$ & $50-55$ \\
\hline Densidade Massica (kg/l) & $0,2-0,25$ & $0,55-0,75$ & $0,75-0,85$ & $\approx 0,20$ & $0,8-0,85$ \\
\hline Densidade Energética (GJ/m $\left.{ }^{3}\right)$ & $2,0-3,0$ & $7,5-10,4$ & $15,0-18,7$ & $6-6,4$ & $18,4-23,8$ \\
\hline Cinzas & Médio & Limitado & Limitado & Alto & Limitado \\
\hline Propriedades Hidroscópicas & Hidrofílico & Hidrofílico & Hidrofóbico & Hidrofóbico & Hidrofóbico \\
\hline Degradação Biológica & Sim & Sim & Não & Não & Não \\
\hline Moabilidade & Baixa & Baixa & Bom & Bom & Bom \\
\hline Manuseio & Especial & Especial & Bom & Bom & Bom \\
\hline
\end{tabular}

Fonte: KEMA, 2010 (adaptado).

Diferentes processos de torrefação tem sido propostos para melhor tratamento da biomassa, tais como a torrefação à seco, torrefação úmida e torrefação via líquido iônico. A torrefacção a seco consiste no aquecimento lento da biomassa numa atmosfera inerte, a partir de $200{ }^{\circ} \mathrm{C}$ a $300{ }^{\circ} \mathrm{C}$, no qual temperaturas superiores não são recomendadas devido à grande liberação de alcatrão e tendência de perda da densidade energética. $\mathrm{O}$ uso de líquidos iônicos através da impregnação da biomassa, visa elevar a taxa de torrefação da celulose a temperaturas inferiores a $300^{\circ} \mathrm{C}$. A torrefação úmida ou prétratamento hidrotérmico através de agua pressurizada produz sólidos com densidade energética maior que a torrefação à seco, no entanto, o gasto energético e custos operacionais tendem a ser mais elevados que as demais técnicas.

Couhert et al. (2009) observaram que a torrefação diminui a razão $\mathrm{O} / \mathrm{C}$ quando utilizado temperaturas mais severas $\left(300^{\circ} \mathrm{C}\right)$ e menor tempo no pré-tratamento da biomassa, favorecendo a quantidade e qualidade do gás de síntese produzido na gaseificação. Além disso, como a torrefacção introduz mudanças na estrutura do material e reduz o seu teor de componentes voláteis, os rendimentos dos produtos da pirólise são também modificadas à medida que aumenta que se aumenta o grau de aquecimento do pré-tratamento (Broström et al., 2012). 


\section{9 a 22 de outubro de 2014 \\ Florianópolis/SC}

Conforme Batidzirai et al. (2013), a maioria das atuais tecnologias de torrefação em desenvolvimento são baseadas em conceitos de reatores já existentes destinados para outros fins, como a secagem ou pirólise e que, portanto, só exigem melhoramentos técnicos para aplicações de torrefação. Assim, não temos uma tecnologia superior à outra, exige apenas que seja observadas as suas vantagens e desvantagens. A seleção adequada do reator é importante pois cada sistema possui características únicas, devendo ser observado os tipos específicos de biomassa a serem utilizadas e suas aplicações (Ciolkosz e Wallace, 2011).

Dessa forma, este trabalho visa apresentar e comparar os principais desenvolvimentos em escala laboratorial das tecnologias utilizadas nos estudos da torrefação, estendendo a análise para diferentes experiências industriais no mundo a partir de diferentes tipos de fontes de biomassa, trazendo aspectos das tecnologias do sistema reacional, balanço de massa e balanço energético do processo de torrefação.

\section{SISTEMAS LABORATORIAIS DE TORREFAÇÃO}

\subsection{Tecnologias, Técnicas e Processos}

Tran et al. (2013) demonstraram que as propriedades do combustível sólido, incluindo os valores de aquecimento e moabilidade das biomassas investigados foram melhorados por torrefação, em reator de leito fixo em bancada. Tanto a temperatura quanto o tempo de reação apresentaram um forte efeito sobre a biomassa torrefeita, sendo os efeitos da temperatura mais fortes do que os efeitos do tempo de reação. Ainda, à mesma temperatura de torrefação, com tempo de reação mais longo, foi obtido melhor qualidade no produto final. No entanto, os tempos de reação muito longos e/ou muito maiores que os usuais diminuiria o rendimento do produto sólido. Neste experimento, o sistema experimental constituiu, basicamente, de um reator tubular colocado num forno elétrico, anexado com sistema de gás inerte com aquecimento e sistema de condensação de voláteis na saída do reator.

O reator de leito fluidizado foi utilizado por Batidzirai et al. (2013) na identificação das características de desempenho do processo, tais como a eficiência térmica e produção de massa, e na discussão dos fatores determinantes da torrefação através da análise dos balanços de massa e energia.

Segundo Bergman et al. (2005) os reatores podem ser classificados como de aquecimento direto ou indireto. Em um reator de aquecimento direto, o meio de aquecimento (fluido) entra em contato direto com a biomassa. No entanto, no aquecimento indireto, o calor é transferido para uma biomassa através da condução (ou seja, o meio de aquecimento não entra em contato com a biomassa). Dessa forma, os tipos mais comuns de reatores utilizados na torrefação são o de aquecimento por convecção, de leito fluidizado, de tambor rotativo e o reator de microondas. Reatores do tipo leito convectivo e fluidizado utilizam aquecimento direto, o de tambor rotativo é um reator de aquecimento indireto, e de microondas é um reator de aquecimento volumétrico. O reator de aquecimento direto tem uma melhor e mais uniforme transferência de calor, enquanto que no aquecimento indireto, os voláteis não são diluídos pelo fluido de aquecimento, e podem ser facilmente utilizados na combustão. 


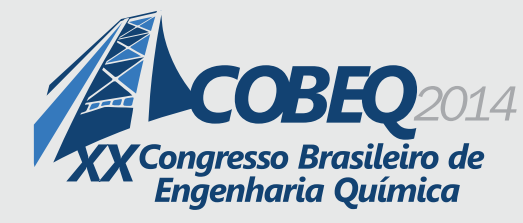

Para examinar alguns efeitos dos reatores na torrefação de biomassa, optou-se pela escolha dos seguintes sistemas: aquecimento convectivo, tambor rotativo, leito fluidizado e microondas. Os reatores de aquecimento convectivo e leito fluidizado são de aquecimento direto, o de tambor rotativo é de aquecimento indireto, já o microondas é um reator de aquecimento volumétrico. Pode ser observado na Tabela 2 os reatores citados, com suas principais vantagens, desvantagens e características. No entanto, deve-se atentar que o produto final será também determinado pelos efeitos de diferentes diâmetros dos reatores, diferentes temperaturas e tempos de residência utilizados, assim como, a qualidade do produto final depende das propriedades físicas da biomassa utilizada, tais como: tamanho, forma, densidade e orientação das fibras.

Tabela 2 - Modelos de reatores para torrefação em escala de bancada

\begin{tabular}{|c|c|c|c|}
\hline Tipo de Reator & Vantagem & Limitações & Características \\
\hline $\begin{array}{l}\text { Aquecimento } \\
\text { convectivo }\end{array}$ & $\begin{array}{l}\text { - Maior ocorrência de reações } \\
\text { exotérmicas, elevando a } \\
\text { temperatura do núcleo da } \\
\text { biomassa. }\end{array}$ & $\begin{array}{l}\text { - Possível ocorrência de } \\
\text { variações de temperaturas ao } \\
\text { longo do reator. }\end{array}$ & $\begin{array}{l}\text { - Os gases inertes aquecidos passam } \\
\text { através de um leito empacotado ou } \\
\text { fixo; } \\
\text { - Reator vertical ou grelha horizontal; } \\
\text { - Transferência de calor de forma } \\
\text { indireta, ocasionando uma maior gasto } \\
\text { energético. }\end{array}$ \\
\hline Tambor rotativo & $\begin{array}{l}\text { - Possibilidade de } \\
\text { aquecimentos direto e indireto } \\
\text { da biomassa. }\end{array}$ & $\begin{array}{l}\text { - Dificuldade no controle de } \\
\text { temperatura; } \\
\text { - Ocorrência de calor radiativo } \\
\text { na superfície do tambor. }\end{array}$ & $\begin{array}{l}\text { - Aquecimento direto ou indireto da } \\
\text { biomassa, podendo ainda um modelo } \\
\text { híbrido; } \\
\text { - Constante mistura da biomassa. }\end{array}$ \\
\hline Leito fluidizado & $\begin{array}{l}\text { - Elevada taxa de transferência } \\
\text { de calor. }\end{array}$ & $\begin{array}{l}\text { - Dificuldade na separação de } \\
\text { material do leito, caso seja } \\
\text { utilizado, a partir de biomassa; } \\
\text { - Arraste de partículas finas. }\end{array}$ & $\begin{array}{l}\text { - Elevado coeficiente de transferência } \\
\text { de calor e uniformidade da temperatura } \\
\text { no leito; } \\
\text { - Alta qualidade da biomassa torrefeita. }\end{array}$ \\
\hline Microondas & $\begin{array}{l}\text { - Menor tempo de } \\
\text { aquecimento e uniformidade } \\
\text { da temperatura; } \\
\text { - Design compacto. }\end{array}$ & $\begin{array}{l}\text { - Sistema conceitual, com } \\
\text { avaliações apenas qualitativas }\end{array}$ & $\begin{array}{l}\text { - Aquecimento através da vibração e } \\
\text { atrito das moléculas ( } 300 \mathrm{MHz} \text { a } 300 \\
\text { GHz); } \\
\text { - Reator de aquecimento volumétrico. }\end{array}$ \\
\hline
\end{tabular}

\subsection{Fenômenos de Massa e Energia na Torrefação}

Todos os fenômenos observados nos tipos de reatores e sistemas de torrefação dizem respeito, de alguma forma, a transferência de massa e calor. Pode-se considerar que o calor do ambiente atinge a superfície das partículas da biomassa, superando a resistência térmica em torno delas. Então, o calor entra no interior da partícula, vencendo a resistência interna. Ocorre do mesmo modo, quando os voláteis da torrefação migram de dentro para fora da biomassa, ultrapassando a resistência à transferência de massa.

Assim, tem-se que no processo de torrefação da biomassa a transferência de massa e calor é afetada por processos condutivos e convectivos, dentre estes fatores: transferência externa de calor, resistência interna à transferência de calor, resistência interna à transferência de massa e transferência 
externa de massa, conforme observado na Figura 1.

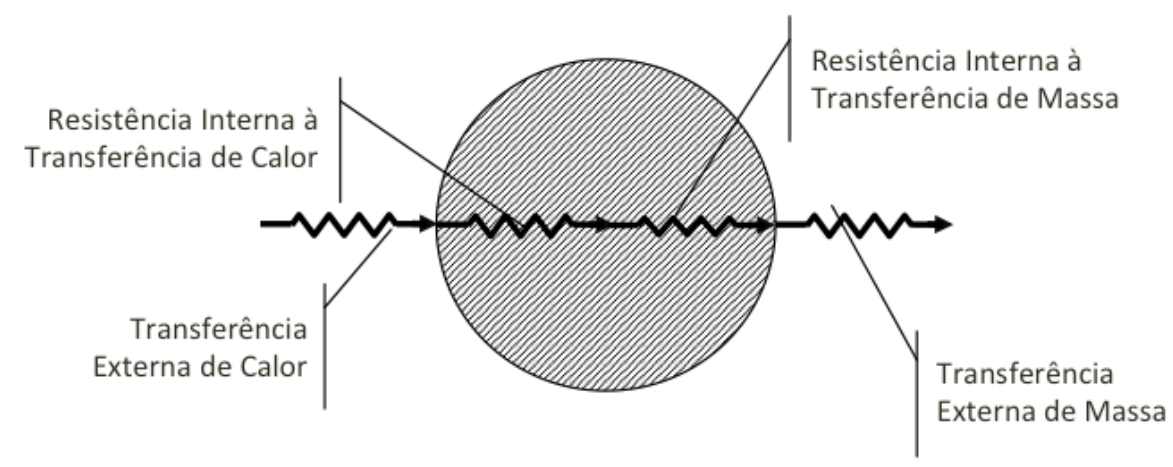

Figura 1 - Parâmetros envolvidos na transferência de massa e calor numa biomassa cilíndrica a ser torrefeita.

A resistência à transferência externa de calor é dependente das propriedades das imediações da biomassa e é fortemente influenciada pelo tipo de reator e o seu modo de operação. A resistência de calor do interior da biomassa é função do tamanho e tipo da biomassa. Quanto a resistência interna à transferência de massa, esta propriedade consiste ao fluxo de voláteis, gerado na biomassa, que migram de dentro para a sua superfície; quanto maior for este percurso de deslocamento, maior é a resistência interna, permitindo uma maior permanência dos voláteis no interior da biomassa, ocasionando em reações exotérmicas. Tais reações aumentam a temperatura interna, que por sua vez aumentam a taxa de evaporação destes voláteis. Este processo continua até quando o equilíbrio dinâmico da perda de calor é atingida. Já a resistência externa de transferência de massa é função do tipo de reator, onde se o meio que circunda a biomassa não permitir a fácil dissipação de voláteis, essa concentração ao redor da biomassa elevaria, dificultando a saída destes produtos, aumentando, novamente, a temperatura da biomassa.

\section{SISTEMAS INDUSTRIAIS DE TORREFAÇÃO}

\subsection{Reatores e Processos Utilizados}

Devido ao seu potencial econômico, a torrefação vem sendo desenvolvida por mais de 60 fornecedores de tecnologia, desenvolvedores e instituições de conhecimento (Schorr et al., 2012). A grande maioria dos projetos de implantação estão sendo realizados, principalmente na Europa e América do Norte.

O que tem-se observado industrialmente é que a torrefação é baseada no princípio de secagem térmica. E, dessa forma, existem muitos métodos potenciais já desenvolvidos e patenteados, que são na grande maioria baseados em diferentes tipos de equipamentos de secagem. No entanto, existem vários desafios que o tornam até então difícil de executar em uma planta comercial de torrefação. Um desses desafios são as características individuais da biomassa e a capacidade de controlar as condições de operação que irão melhorar a qualidade dos produtos torrefeitos a baixo custo (Acharya 
et al., 2012). A Tabela 3 apresenta as principais vantagens e desvantagens dos diferentes tipos de reatores utilizados industrialmente.

Tabela 3 - Principais vantagens e limitações de diferentes tipos de reatores industriais utilizados para torrefação de biomassa energética

\begin{tabular}{|c|c|c|}
\hline Tipo de Reator & Vantagens & Limitações \\
\hline Tambor Rotativo & $\begin{array}{l}\text { - Equipamento relativamente simples. } \\
\text { - Perda de pressão. } \\
\text { - Possibilidade de aquecimento direto } \\
\text { e indireto. }\end{array}$ & $\begin{array}{l}\text { - Baixa transferência de calor (especialmente em } \\
\text { sistemas de aquecimento indireto). } \\
\text { - Dificuldade na medição e controle da } \\
\text { temperatura. } \\
\text { - Maior tamanho do sistema. } \\
\text { - Necessária vedação adequada do cilindro. } \\
\text { - Sistema de difícil de ampliação. }\end{array}$ \\
\hline Leito Móvel & $\begin{array}{l}\text { - Sistema de fácil operação e } \\
\text { construção simples. } \\
\text { - Boa transferência de calor. } \\
\text { - Leito de alta densidade. }\end{array}$ & $\begin{array}{l}\text { - Queda de pressão significativa. } \\
\text { - Difícil controle da temperatura. }\end{array}$ \\
\hline Tipo Parafuso & $\begin{array}{l}\text { - Fluxo empistonado. } \\
\text { - Tecnologia madura para torrefação. }\end{array}$ & $\begin{array}{l}\text { - Apenas aquecimento indireto. } \\
\text { - Maior possibilidade de "hot spots". } \\
\text { - Baixa taxa de transferência de calor. } \\
\text { - Dificuldade de scale-up. } \\
\text { - Requer adequada vedação do eixo. }\end{array}$ \\
\hline $\begin{array}{l}\text { Forno de Múltiplo } \\
\text { Aquecimento }\end{array}$ & $\begin{array}{l}\text { - Design de equipamento comprovado } \\
\text { para secagem. } \\
\text { - Grande possibilidade de scale-up. } \\
\text { - Fácil controle de temperatura e } \\
\text { tempo de residência. }\end{array}$ & $\begin{array}{l}\text { - Menor taxa de transferência de calor em } \\
\text { comparação com outros reatores diretos. } \\
\text { - Capacidade volumétrica limitada. } \\
\text { - Reatores relativamente maiores. } \\
\text { - Requer adequada vedação do eixo. }\end{array}$ \\
\hline Leito Fluidizado & $\begin{array}{l}\text { - Excelente taxa de transferência de } \\
\text { calor. } \\
\text { - Fácil transposição de escala. }\end{array}$ & $\begin{array}{l}\text { - Exige menor tamanho de partícula. } \\
\text { - Necessidade de gás de arraste. } \\
\text { - Necessidade de sistema adicional } \\
\text { fluidização. } \\
\text { - Dificuldade de fluxo empistonado. }\end{array}$ \\
\hline
\end{tabular}

Fonte: Acharya et al., 2012 (adaptado).

A escolha correta de um reator para a torrefação é primordial, já que cada reator tem propriedades distintas e pode lidar com tipos específicos de biomassa. Ainda, não há nenhuma análise comparativa dos tipos de reatores, em operação, para torrefação. Em vez disso, os detentores da tecnologia defendem os seus próprios projetos, alegando superioridade sobre os demais. A ciência da torrefação carece, assim, uma análise comparativa de reatores independente.

\section{CONCLUSÕES}

Conforme visto, nos processos de torrefação a temperatura do sistema, o tempo de residência, tipo de biomassa e o tamanho da partícula, influenciam de forma direta nos parâmetros de qualidade (produção de massa, rendimento de energia, densidade energética) da biomassa torrefeita. Ou seja, em um determinado sistema/reator, a produção de massa varia de acordo com o conjunto de parâmetros escolhidos. Para um determinado conjunto de parâmetros, a produção de massa também varia de um 
reator para outro. Assim como, temos que os rendimentos mássicos e energéticos de uma biomassa torrefeita indicam o rendimento total do processo de torrefação.

Ainda, que o processo ótimo de torrefação depende de vários fatores técnicos, dentre outros econômicos, tais como o tipo de matéria-prima, as especificações dos produtos desejados, o desenho técnico do reator/sistema e as variações técnicas para integração do aproveitamento de calor e emissões de voláteis.

Dessa forma, para comparação de tecnologias de reatores (mencionados neste trabalho) potenciais para a torrefação, faz-se necessário a sua comprovação prática e que seja versátil o suficiente para acomodar todas as condições de operação, incluindo a capacidade de: fácil controle de temperatura e tempo de residência, possuir ampla gama de formas de alimentação, possuir um sistema integrado de calor para recirculação no processo, capacidade de scale-up, fornecer aquecimento uniforme, proporcionar alta taxa de aquecimento, ter elevada transferência de calor e massa e operar grandes e pequenas partículas.

\section{REFERÊNCIAS}

ACHARYA, B.; SULE, I.; DUTTA, A. A review on advances of torrefaction technologies for biomass processing. Biomass Conv. Bioref., 2:349-369, 2012.

ARIAS, B., PEVIDA, C., FERMOSO, J., PLAZA, M.G., RUBIERA, F., PIS, J.J. Influence of torrefaction on the grindability and reactivity of woody biomass. Fuel Process. Technol., v. 89, p. 169-75, 2008.

BASU, P.; SADHUKHAN, A. K.; GUPTA, P.; RAO, S.; DHUNGANA, A.; ACHARYA, B. An Experimental and Theoretical Investigation on Torrefaction of a Large Wet Wood Particle. Biores. Techn., 2014.

BATIDZIRAI, B.; MIGNOT, A.P.R; SCHAKEL, W.B.; JUNGINGER, H.M.; FAAIJ, A.P.C. Biomass torrefaction technology: Techno-economic status and future prospects. Energy, v. 62, p. 196 $-214,2013$.

BERGMAN, P.C.A.; BOERSMA, A.R.; ZWART, R.W.H.; KIEL, J.H.A. Development of torrefaction for biomass co-firing in existing coal-fired power stations "biocoal". ECN Report, ECNC-05-013, 2005.

BROSTRÖM, M.; NORDIN, A.; POMMER, L.; BRANCA, C.; BLASI, C.D. Influence of torrefaction on the devolatilization and oxidation kinetics of wood. J. Anal. Appl. Pyrol, v. 96, p. 100-109, 2012.

CIOLKOSZ, D.; WALLACE, R. A review of torrefaction for bioenergy feedstock production. Biofuel Bioprod. Bior., 2011.

COUHERT, C.; SALVADOR, S.; COMMANDRÉ, J.M. Impact of torrefaction on syngas production from wood. Fuel, v. 88, p. 2286-2290, 2009. 
KEMA. Statusoverzicht en impactanalyse van torrefaction in Nederland, in opdracht van Agentschap NL, rapportnummer 30920555-Consulting 10-0508, 2010.

MEDIC, D.; DARR, M.; SHAH, A.; POTTER, B.; ZIMMERMAN, J. Effects of torrefaction process parameters on biomass feedstock upgrading. Fuel, v. 91, p.147-154, 2012.

PIMCHUAI, A.; DUTTA, A.; BASU, A. Torrefaction of agriculture residue to enhance combustible properties. Energy Fuels, v. 24, p. 4638-4645, 2010.

SARVARAMINI, A.; ASSIMA, G.P.; LARACHI, F. Dry torrefaction of biomass - Torrefied products and torrefaction kinetics using the distributed activation energy model. Chem. Eng. J., p. 498-507, 2013a.

SARVARAMINI, A.; GRAVEL, O.; LARACHI, F A. Torrefaction of ionic-liquid impregnated lignocellulosic biomass and its comparison to dry torrefaction. Fuel, v. 103 , p. 814-826, 2013b.

SCHORR, C.; MUINONEN, M.; NURMINEN, F. Torrefaction of biomass. Mikkeli, Finland: Miktech Ltd/Centre of Expertise-programme; p. 55, 2012.

TRAN, K.Q.; LUO, X.; SEISENBAEVA, G.; JIRJIS, R.; Stump torrefaction for bioenergy application. Appl. En., v. 112, p. 539-546, 2013. 